\title{
Note on Documentation
}

I use a modified version of Library of Congress in transliteration from Cyrillic, and I follow University of Chicago style (I 5 th edition) in my system of references. The transliteration from Cyrillic of proper names is, as always, a problem. I use conventional English spelling for last names and places, and where necessary I supply the Library of Congress transliteration or alternative spellings for last names in the Selected Bibliography. It should be kept in mind that nineteenth-century Russia used the so-called Old Style (OS) Julian calendar, which was twelve days behind the New Style (NS) Gregorian calendar used in Western European countries at the time. Where two dates are provided for one event, they refer to these two time systems. On these occasions, the New Style (European) date is always in parentheses. All translations from the Russian, unless otherwise noted, are mine. 

Consequences of Consciousness 
